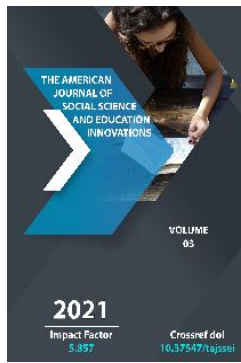

Journal Website: http://theamericanjour nals.com/index.php/taj ssei

Copyright: Original content from this work may be used under the terms of the creative commons attributes 4.0 licence.

\section{On The Intonation Of Communicative Types Of Sentence In Turkology}

Maftuna Muhammadovna Gaziyeva

Senior Lecturer Of The Department Of Linguistics, Doctor Of Philosophy In Philology, Fergana State University, Uzbekistan

\section{Zamira Rahmonova}

Teacher Of Academic Lyceum Fergana Branch Of Tashkent University Of Information Technologies, Uzbekistan

\title{
ABSTRACT
}

The article explores the history of research on the intonation features of communicative types of sentence. It also highlights problematic issues of intonation and prosody and points to their solutions.

\section{KEYWORDS}

Intonation, prosody, accent, melody, tempo, timbre, intonation of communicative types of sentence 
In Turkology, a number of researches on prosodicism and intonation are also considered. In this regard, devoted to the

intonation of communicative types of speech A.U.Turkbenbaev, Sh.K.Kaliev, I.E.Alekseev, S.Kurenov, A.Nurmuhamedov, A.Sapaev, O.D.Rozieva,I.Chanakov, J.Duyishev [30. 20. 5 . 6. 7. 2. 17.] can show the work of. These works are mainly characterized by the fact that linguistics is devoted to the field of syntactic phonetics and they are experimental-phonetic studies based on the intonographic method. Experimental and phonetic researches conducted in the 1960 s and 1980 s examined communicative types of intonation in Kazakh, such as simple sentences, intonation of sentences, interrogative sentences in Yakut, intonation of sentences in Turkmen, and intonation of sentences in Kyrgyz. . Of course, the above research in the field of experimental phonetics was carried out in special scientific laboratories, the intonological equipment in the laboratories served to show the acoustic parameters of speech, the scientific conclusions are the basis for the creation of theories in Turkology. However, in the process of reviewing the work in this area, it was observed that some of the conclusions obtained as a result of experiments on the prosodic structure of speech lack consistency. These are, firstly, not clearly visible because the diagrams showing some parameters of the melodic movement are drawn by hand. Second, the movement of intonation components during the experiment does not have a visual image. Third, the place of words in a speech or speech fragment experiment is not reflected in diagrams showing prosodic means. Nevertheless, experimental-phonetic experiments on prosodic means or intonation components have served as a scientific-theoretical source for the creation of literature in this field.

\section{MATERIALS AND METHODS}

Even today, the problem of intonation and prosody remains one of the most important issues in Turkology. In this regard, the doctoral dissertation of H.H. Salimov [18] devoted to the study of the prosodic system of the Tatar language is significant. It first gives linguistic explanations for the terms prosody and intonation. Then the attitude to the works of the great representatives of this field in Russian linguistics V.A. Artemov, Yu.A. Dubovsky, L.P. Blokhina, R.K. Potapova, N.D. Svetazarova. At the same time, special attention is paid to the work done in the comparative-typological aspect related to the prosodic construction of Russian, English and German languages. It is emphasized that the main tone of the prosody covers the frequency, length, intensity, timbre and pause, and the functional properties of these instruments are highlighted. It is noted in this study that Kazakh and Azerbaijani scientists are leading the research in the field of prosody.

The article of the Kazakh linguist Z.M. Bazarbaeva [3] is distinguished by the fact that it focuses on the study of pragmatic features of intonation. In the scholar's observations, intonation is recognized as a means of shaping oral speech, through which the communicative-pragmatic and emotionally-expressive features of expression are revealed. Speech sounds and intonation perform a communicative function using acoustic parameters such as basic tone frequency, length, and intensity. In oral 
speech, meanings and accents expressed through intonational and prosodic components are separated by punctuation marks in written speech. In this work, special attention is paid to the issues of the theory of actual division of speech in showing the pragmatic features of prosodic means.

A number of researches in the field of phonetics and phonology in Uzbek linguistics [15. 1.], most of which are characterized by the fact that the segment is devoted to phonetic issues. Professor A. Gulomov [29] is one of the first scholars in Uzbek linguistics to study issues in the field of prosodics using a subjective method. Experimental-phonetic researches on prosodics and intonation in Uzbek linguistics are numerous. Such researches are A.Mahmudov, D.Niyozov, H.Yuldasheva, M.Yusupova, N.Hayitmetov, U.Tuychiev, M.Mirtojiev [8. 12. 23. 25. 27. 21. 11.] is seen in the scientific work of scholars such as. These experimental-phonetic researches in the field of prosody were carried out with the help of equipment and devices created 40-50 years ago. However, the scientific conclusions obtained are still used today. This also indicates the great need for experimental research in the field.

In the 6os of the XX century he prepared a dissertation on "The intonation of the modern Uzbek literary language" by DM Niyazov [12]. It studies issues such as language and speech, communicative types of speech, classification of verbs. It shows the sequence of performing experimental-phonetic analysis in the study of intonation. This sequence consists of communicative analysis of experimental materials, selection of announcers and tape recording of speech, audience analysis, electro-acoustic analysis of physical properties of intonation, structural analysis of experimental data. In the main part of the work, the peculiarities of the intonation of the verb are studied through the emphasis, the pronunciation of the tempo, the movement of the main tone. The physical properties of Darak sentences have been studied in parameters such as average length in the joint, average total energy in the joint pronunciation, frequency range and level, change in base tone frequency and frequency interval, rate of change in base tone frequency. On the basis of scientific conclusions obtained through experimental phonetic research, the pronouns are classified, their specific features are shown.D. Niyazov, who conducted an experiment on the intonation of Darak sentences, focused on identifying the differences between these types. The author of the study distinguishes eight types of expression: "pure message, message, announcement, affirmative answer, negative answer, counting in the tree, naming, bite. None of the communicative types of speech listed are clearly distinguished, but each of them differs from each other by a complex of intonational signs, and at the same time unites under the general intonation structure of the speech "[13,65]. There is no objection to the author's views on word types. However, although the formation of sentence types takes place through a prosodic medium, in the structure of the new intonational model a number of meanings such as message, bite, denial, affirmation, request may also be implicitly given. This is, of course, seen in the expression of speech acts through the intonation medium. The speaker gives the necessary speech acts in the process of communication in the structure of intonation construction. At this point, we would like to emphasize the need to differentiate speech 
acts by speech types, but also to the fact that a message or message emerges through a prosodic medium.

H. Yuldasheva's dissertation on the topic "Intonation of interrogative sentences in modern Uzbek literary language" is one of the most significant works in the field [23, 16-63]. One of the main achievements of the work is seen in the separation and analysis of flat, rising and falling tones associated with changes in the frequency of the main tone in speech. He scientifically substantiates the models of interrogative sentences by experimentally studying the melodic structure of interrogative sentences in Uzbek. In this work, the basic concepts of speech melody are defined as "melodic movement", "melodic range", "melodic peak", "rising", "descending" and "flat" tone associated with the change of the main tone. In particular, "the melodic structure consists of melodic movement. The melodic movement consists of smooth, descending, rising tones motiv Each sentence has its own melodic peak and minimum performance "[24, 9] and this intermediate limit is called the melodic range. Experimental research by $\mathrm{H}$. Yuldasheva is aimed at studying the intonation of interrogative sentences and various positional changes in them. It mainly studies issues such as "the temporal component of intonation, the relationship of acoustic parameters in the intonation of the interrogative speech, the pause in the interrogative sentences" [22]. The tasks set in this dissertation have been perfectly fulfilled. However, the scientific conclusions from the experimental-phonetic studies are not high, as the diagrams related to the change in the frequency of the main tone and the movement of the intensity in the accent are drawn manually. There are also differences in our observations on issues such as melodic peak, intensive peak, and distribution of stress in the joints.

In Uzbek linguistics, a number of studies on phonetics appeared in the $80 \mathrm{~s}$ of the last century. Opinions on phonology in the existing literature, in particular, the separation of segment and supersegment units at the phonetic-phonological level as a result of differentiation of phonetics and phonology, theoretical conclusions through experimental research, preliminary data on the method and methodology of phonetic-phonological research [15, 30- 32]. However, although this information was given briefly as required by the textbook, it served as the basis for future research work. From the 80s and 90s, theories of phonology were formed in Uzbek linguistics, and the concept of language and speech began to be applied to these phenomena. This has led to an expansion of the field of scientific research, even in terms of lower-level units of language. If the prosodic means were originally the object of experimental research, and the work was carried out mainly of a practical nature; Beginning in the 1990s, research in this area began to show a theoretical character. First, in 1990, the creation of Professor A. Nurmanov's "Phonology and Morphonology of the Uzbek language", and later the work of A. Abduazizov of the same name led to the classification of phonetic units on the basis of language and speech dichotomy [15. 1.]. Due to this, there was a need to separate language and speech units in the system of prosodic means as well. Professor A.Abduazizov noted the need to "establish a certain relationship between phonetic units (sound, syllable, stress, intonation) and phonological units (phoneme, syllable, accentema, intonema)" [1, 
13], the issues of classification of their functional aspects, the main and current problems in the study of phoneticphonological level units were identified. The study, analysis of the functions and features of these units in the process of communication helps to gain a deeper understanding of the linguistic features of the units of the prosodic level, as they differ as syllables, accents and intonation, their functional aspects, language and speech units. In the study of phonetic-phonological units, the study of problems in two or more disciplines, that is, the study of linguistics in relation to physics, physiology and biology, has provided an opportunity to obtain new scientific results. This helped to solve unsolved problems in science. In this area, a number of studies have been conducted in Uzbek linguistics, which have served to reveal the functional aspects of the phoneticphonological level units. The views expressed in the work of the famous linguist A. Gulom "Emphasis on the Uzbek language" [29] will be the theoretical basis for further research in this area. In particular, A.Mahmudov [8], based on the theoretical views of A.Gulamov, studied the emphasis experimentally and continued the work on experimental phonetics in Uzbek linguistics.

Speaking of emphasis, Professor M. Mirtojiev [10, 24-31. 11, 175] was of great service. Mirtojiev completely denies that the Uzbek accent is dynamic, saying that the phonetics of the Uzbek language were first studied by Russian Turkologists, and as a result, the views on the Russian accent were applied to the Uzbek language. He notes that this theory was repeated because the leaders of the experts who later conducted research on the subject were Russian scientists, and that it is still moving mechanically from textbook to textbook. Given that language is a "dynamic phenomenon that is constantly growing and evolving" $[16,61]$, the characteristics of its units can also change constantly.

Different interpretations of the lexical emphasis of the Uzbek language have emerged accordingly. Speaking of lexical stress, the scholar also distinguishes and classifies auxiliary stress. Experimental research conducted by Mirtojiev is based on traditional methods, comparing them with the conclusions of new experiments, clarifying the analysis helps to shed light on the problems in this area.

\section{RESULTS AND DISCUSSIONS}

There is a wide range of research on the study and analysis of intonation and its components, which is a prosodic tool in Uzbek linguistics. In studying intonation, scholars have focused more on its function within the syntactic level. Because intonation distinguishes communicative types of speech, along with grammatical means, it realizes the content they express (question, command in sentences). "The intonational aspect of a speech is related to its content and structure: the division of speech into parts is based on grammatical-intellectual and intonational aspects. The division of a sentence into parts can be from several aspects: from the logical side (parts of content), from the formalgrammatical side (grammatical parts), from the phonetic side (intonation parts). But these aspects are interconnected: they will be compatible with each other. Analysis of the various means of language, which is a tool for knowing the real being, shows that intonation alone has no intellectual content in terms of 
language: it exists through speech, so intonation is an auxiliary means of language: the supersegment is a phonetic phenomenon " $[28,44]$. In the process of communication, intonation becomes the main means of speech. In speech without intonation, the difference between a phrase and a sentence, a question or a statement, a command or a request is not known. Intonation is one of the main means of developing the speaker's attitude in the process of communication.

In the work "Phonetics of the Uzbek language" M. Mirtojiev expressed his views on the communicative types of speech: intonation, interrogation, command and desire. Although work has been done on the intonation of interrogative and interrogative sentences, experimental ideas about the intonation of command and desire sentences are one of the first steps in this direction. In this sense, Professor A.Nurmonov comments on the views in the book "Phonetics of the Uzbek language": "It is true that A.Gulam gave valuable ideas about the features and types of stress in the Uzbek language, and these ideas were confirmed by A.Mahmudov on the basis of experimental phonetics. The author ( $M$. Mirtojiev) creatively used these materials. The intonation of speech in the Uzbek language is still insufficiently studied. There is only $\mathrm{H}$. Ismatullaev's dissertation devoted to the intonation of interrogative sentences. But the intonation of the command words, their peculiarities, do not exist as long as they are the object of special research. To do this, an experimental phonetics laboratory should be set up. Nevertheless, the author thinks about the intonation of words, questions, commands "[14, 345]. In this way, Professor A.Nurmonov points out that M.Mirtojiev's views on the intonation of words, questions and commands were summarized using subjective analysis, without the results of experimental research. Also, Mirtojiev's ideas about the intonation of syntactic units attached to a sentence: cohesive parts, separate parts, impulses, consonants, introductory words, intonations and intonations are the first attempts in Uzbek linguistics. Of course, since the traditional experimental results are given in the work, there are some analytical points in the conclusions, and it is one of the main problems of linguistics to compare these shortcomings with the results obtained with the help of modern technical devices.

Intonation and logical emphasis are the most important factors that actualize a sentence. $O$. Bazarov “... intonation distinguishes the informative core of a sentence, theme and rhymes according to its logical-communicative function. It is seen as a means of turning a sentence into a sentence, in particular, of a means of actualizing a particular passage. In addition to the intonation, which is a prosodic means, the main component of the actualizing means is the logical emphasis and, in connection with it, the introduction of the tempo and pause of speech "[4,74]. According to the grammatical rules of the Uzbek language, the location of the logical stress corresponds to the part before the cut. In some places the logical emphasis and the location of the rhyme are recorded in one place, while in other situations their structure differs sharply from one another. While Rema's main task is to convey new information to the speaker, the function of logical emphasis in speech is to highlight a passage. Professor M. Mirtojiev states that "the emphasis on logic is not related to lexical emphasis, even on auxiliary words that do not 
have lexical emphasis" [11,175]. Communication is a comprehensive process that also has the ability to highlight tools. The emphasis on logic in the auxiliary "with" in the example of writing with a pen means the means.

The second period related to the process of studying prosodic means was called the period of experimental research. During this period, the prosodic features of speech were analyzed using experimental methods using special devices (otsillograph, intonograph) and scientific conclusions were drawn as a result of statistical analysis. This period is called the traditional period of experimental research in science. Although the acoustic properties of the point have been studied in studies using traditional methods, its application in practice has not been carried out.

The third period associated with the study of prosodic means is related to the differentiation of phonetic-phonological fields, the emergence of periods of observation and theoretical stage in science. The emergence of theories of phonology, the beginning of the process of distinguishing language and speech phenomena, ushered in a new era associated with the study of the functional properties of prosodic means. As a result, a theory of a new intonational construction inherent in prosodic means emerged in science. Scientific paradigms inherent in the higher level of language began to find expression in the lower level as well. The paradigm of prosodic means of language has emerged. The functional features of prosodic means in this period began to influence not only the denotative structure of syntactic units, but also their grammatical structure. Therefore, the views of the great scholar A. Gulom on phonetic syntax can be described as a syntactic paradigm of intonation.

\section{CONCLUSION}

It seems that in Turkic studies there has been research on the study of prosodic issues, but many aspects of the content of the field have not been adequately addressed.

\section{REFERENCES}

1. Abduazizov A. Phonology and morphology of the Uzbek language. -Tashkent: Teacher, 1992. - B. 13.

2. Alekseev I.E. Voprositelnye predlojenie $\mathrm{v}$ yakutskom yazyke: Avtoref. diss. ... cand. filol. science. - Alma Ata, 1983.

3. Bazarbaeva Z.M. Issledovanie intonatsii v pragmalingvisticheskom aspekte // Mejdunarodnyy zhurnal prikladnyx i fundamentalnyx issledovaniy. - № 3, 2015. p. 114-118.

4. Bazarov O. Communicative (actual) structure of speech in Uzbek language: Philol. fan. nomz. ... diss. - Fergana, 2004. B. 74 .

5. Duyeshev Zh. Intonation of a declarative sentence in the Kyrgyz language: Author's abstract. diss. ... Cand. philol. sciences. Frunze, 1975.

6. Kaliev Zh.K. On the question of the intonation of a narrative phrase in the Kazakh language. - In the book: Phonetics 
of the Kazakh language. - Alma-Ata, 1969 p. 101-107.

7. Mahmudov A. Slovenian accents in the Uzbek language. - Tashkent: Fan, 1960.

8. Mahmudov A. Phonetic and lexical features of language // Uzbek language and literature. - Tashkent, 1976. - Issue 6. - B. 65.

9. Mirtojiev M. Lexical emphasis in Uzbek language // Uzbek language and literature. Tashkent, 2011. - Issue 3. - B. 24-31;

10. Mirtojiev M. Phonetics of the Uzbek language. - Tashkent: Fan, 2013. - Б. 175.

11. Niyazov D.M. Intonation of narration in modern Uzbek literary language: Author. diss. ... Kand. filol. science. - Tashkent, 1969

12. Niyozov D. Intonation of Darak gaplar // Uzbek language and literature. - Tashkent, 1968. - Issue 5. - B. 64-67.

13. Nurmonov A. Selected works. Volume III. // Professor Miraziz Mirtojiev - phonetist. Tashkent: Akademnashr, 2012. - B. 345.

14. Nurmonov A. Phonology and morphology of the Uzbek language. - Tashkent: Teacher, 1990;

15. Nurmonov A. Methodology and methods of linguistic research. - Tashkent: Akademnashr, 2010. - B. 61.

16. Rozieva O.D. Intonation povestvovatelnogo predlojeniya $\mathrm{v}$ sovremennom turkmenskom yazyke: Avtoref. diss. ... cand. filol. science. Ashgabat, 1975.
17. Salimov X.X. Prosodicheskaya sistema tatarskogo yazyka: Avtoref. diss. ... D-ra filol. science. - Elabuga, 1999. // www.dissercat.com. (application date: 1.08.2018.).

18. Sodiqov A., Abduazizov A., Irisqulov $M$. Introduction to Linguistics. - Tashkent: Teacher, 1981. - B. 30-32.

19. Turkbenbaev A.U. Intonation of simple interrogative sentences in the Cossack language: Author's abstract. diss. ... Cand. philol. sciences. - Alma-Ata, 1966.

20. Toychiev U. Examination of the Uzbek language by the method of experimental phonetics // Uzbek language and literature - Tashkent, 1993. - Issue 4. - B. 13-21;

21. Yuldasheva $\mathrm{H}$. Pause in questioning // Uzbek language and literature. - Tashkent, 1978. - Issue 3. - B. 29-31; Temporal component of intonation // Uzbek language and literature. - Tashkent, 1985. Issue 5. - B. 41-42; Interrelation of acoustic parameters in interrogative intonation // Uzbek language and literature. - Tashkent, 1980. - Issue 2. - B. 49-51.

22. Yuldasheva X. Intonation voprositelnyx fraz sovremennogo uzbekskogo literaturnogo yazyka: Diss. ... Kand. filol. science. Tashkent, 1988. - C. 16-63.

23. Yuldasheva X. Intonation voprositelnyx fraz sovremennogo uzbekskogo literaturnogo yazyka (eksperimentalno-foneticheskoe issledovanie): Avtoref. diss. ... cand. filol. science. - Tashkent, 1988. - C. 9.

24. Yusupova M. Intonation features of syntagma in Uzbek language // Uzbek 
language and literature. - Tashkent, 1979. -

Issue 1. - B. 78-82;

25. O'rinboev B. Modern Uzbek style of speech. - Tashkent: Fan, 1991. - B. 41.

26. Hayitmetov N. Emphasis on logic in the poems of Alisher Navoi: Philol. fan. nomz. ... diss. avtoref. - Tashkent, 1989;

27. Gulomov A., Askarova M. Modern Uzbek literary language. - Tashkent: Teacher, 1987. - B. 44.

28. Gulomov A. Emphasis in Uzbek. - Tashkent, 1947.

29. Chanakov I. Intonation of an interrogative sentence in the Kyrgyz language: Author's abstract. diss. ... Cand. philol. sciences. Frunze, 1980.

30. Oripova, G. (2019). Uzbek poetry and the world literature in the years of independence. Scientific Journal of Polonia University, 32(1), 116-120.

31. Oripova Gulnoza Murodilovna. (2019). The peculiarities of vazn meter in uzbek poetry of the independence period. International Journal of Anglisticum. Literature, Linguisitcs and Interdisciplinary Studies. Volume: 8 /Issue:2/. - Macedonia, 2019. P.33-39. 